\title{
Congenital diaphragmatic hernia-does the presence of a hernia sac improve outcome? A systematic review of published studies
}

\author{
Arimatias Raitio $^{1,2} \cdot$ Adeline Salim $^{1} \cdot$ Paul D. Losty ${ }^{1,3}$ \\ Received: 3 June 2020 / Revised: 4 August 2020 / Accepted: 10 August 2020 / Published online: 17 August 2020 \\ (C) The Author(s) 2020
}

\begin{abstract}
Early reports have suggested survival benefits associated with a hernia sac in congenital diaphragmatic hernia (CDH). However, these studies have included only small subsets of patients. This systematic review aimed to evaluate differences in outcomes of $\mathrm{CDH}$ newborns with and without a hernia sac. PubMed and Embase databases were searched using relevant key terms. Papers were independently reviewed by two authors with final selection approved by the senior author. Original search retrieved 537 papers; the final review included 8 studies ( $n=837$ patients). There were $168 \mathrm{CDH}$ patients $(20 \%)$ with a hernia sac with an overall survival of $93 \%$ vs $73 \%$ for $\mathrm{CDH}$ newborns without a sac $(p<0.001)$. Twenty-three percent of patients with a CDH sac required diaphragm patch repair vs $44 \%$ patients without a sac $(p<0.001)$. Pulmonary hypertension was manifested in $44 \%$ of CDH babies with a hernia sac vs $64 \%$ without a sac $(p<0.001)$. Three studies compared ECMO requirement: $15 \%$ with a hernia sac and $34 \%$ without sac, $p<0.001$.

Conclusion: This study shows significant survival benefits in newborns associated with presence of a CDH sac. This may be likely related to these infants having more favourable physiology with less severe pulmonary hypertension and/or smaller anatomical defects requiring primary closure only.
\end{abstract}

What is Known:

- Early reports have suggested survival benefits associated with a hernia sac in CDH.

- Previous studies have included only a small number of patients.

What is New:

- A systematic review of published studies clearly shows that CDH newborns with a hernia sac have better overall survival outcomes and less severe pulmonary hypertension.

- ECMO utilization and patch repair were also less often required in newborns with a hernia sac.

Keywords $\mathrm{CDH} \cdot$ Congenital diaphragmatic hernia $\cdot$ ECMO $\cdot$ Hernia sac $\cdot$ Survival

\section{Communicated by Piet Leroy}

Paul D. Losty

Paul.Losty@liv.ac.uk

Arimatias Raitio

arimatias.raitio@fimnet.fi

Adeline Salim

adeline.salim@ doctors.org.uk

1 Department of Paediatric Surgery, University of Liverpool, Alder Hey Children's Hospital NHS Foundation Trust, Eaton Road, Liverpool L12 2AP, UK

2 Department of Paediatric Surgery, University of Turku and Turku University Hospital, Turku, Finland

3 Institute of Child Health, University of Liverpool, Liverpool, UK

\section{Abbreviations \\ $\mathrm{CDH}$ Congenital diaphragmatic hernia \\ ECMO Extracorporeal membrane oxygenation \\ LOS Length of stay}

\section{Introduction}

Congenital diaphragmatic hernia $(\mathrm{CDH})$ is the result of diaphragm maldevelopment during foetal life giving rise to pathological herniation of abdominal viscera into the thorax which impacts on normal lung growth associated with pulmonary hypoplasia and hypertension [1]. CDH has an incidence of 1 in 2500 to 3000 live births [2, 3]. 
Despite current advances in neonatal intensive care, $\mathrm{CDH}$ is still associated with an unacceptably high mortality and morbidity [4-6]. Risk factors for poor prognosis currently include liver herniation ('liver up'), large defect size (type ' $C$ ' and ' $D$ ' lesions) and aberrant pulmonary developmental biology [6-10].

In most cases, $\mathrm{CDH}$ consists of a direct anatomical defect communicating between the thoracic and abdominal cavities. The presence of a hernia sac with $\mathrm{CDH}$ is reported in approximately some $20 \%$ of cases [11, 12]. It has been postulated that the presence of a hernia sac may be associated with a better prognosis [11-15]. Although early reports have portrayed survival benefit associated with a hernia sac, this has not been consistent in all studies [16]. Moreover, due to the rarity of a $\mathrm{CDH}$-associated hernia sac, most studies to date have also only described small numbers of patients presenting with a sac anomaly $[13,15,16]$.

Against this background, we have therefore undertaken a systematic review study to critically evaluate "Does the presence of a hernia sac in $\mathrm{CDH}$ newborns equate with better overall prognosis?"

\section{Methods}

\section{Identification and selection of studies}

A comprehensive search of the published literature in PubMed and Embase databases was performed based on PRISMA (Preferred Reporting Items for Systematic Reviews and MetaAnalyses) guidelines [17]. The following terms were used as keywords: 'congenital diaphragmatic hernia' and 'Bochdalek hernia' and 'CDH' in combination with term 'sac'. All articles published up to December 31, 2019, were included in the review.

\section{Inclusion and exclusion criteria}

This study included all original articles reporting on outcomes of neonatal presentation of congenital diaphragmatic hernia with hernia sac. Non-English language papers and case reports ( $<3$ patients) were excluded with title and abstract screening. We also excluded studies on late presentations of hernia beyond the neonatal period, acquired defects, other types of diaphragmatic hernia (Morgagni and hiatus/para-oesophageal) and diaphragmatic eventrations (Fig. 1).
Fig. 1 PRISMA study selection flow diagram
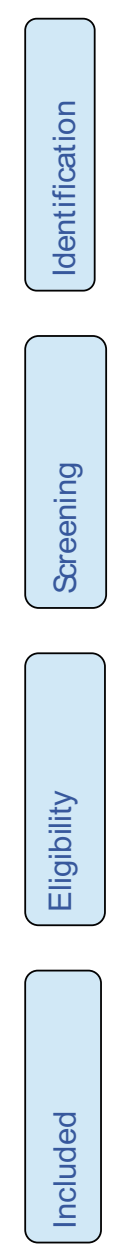
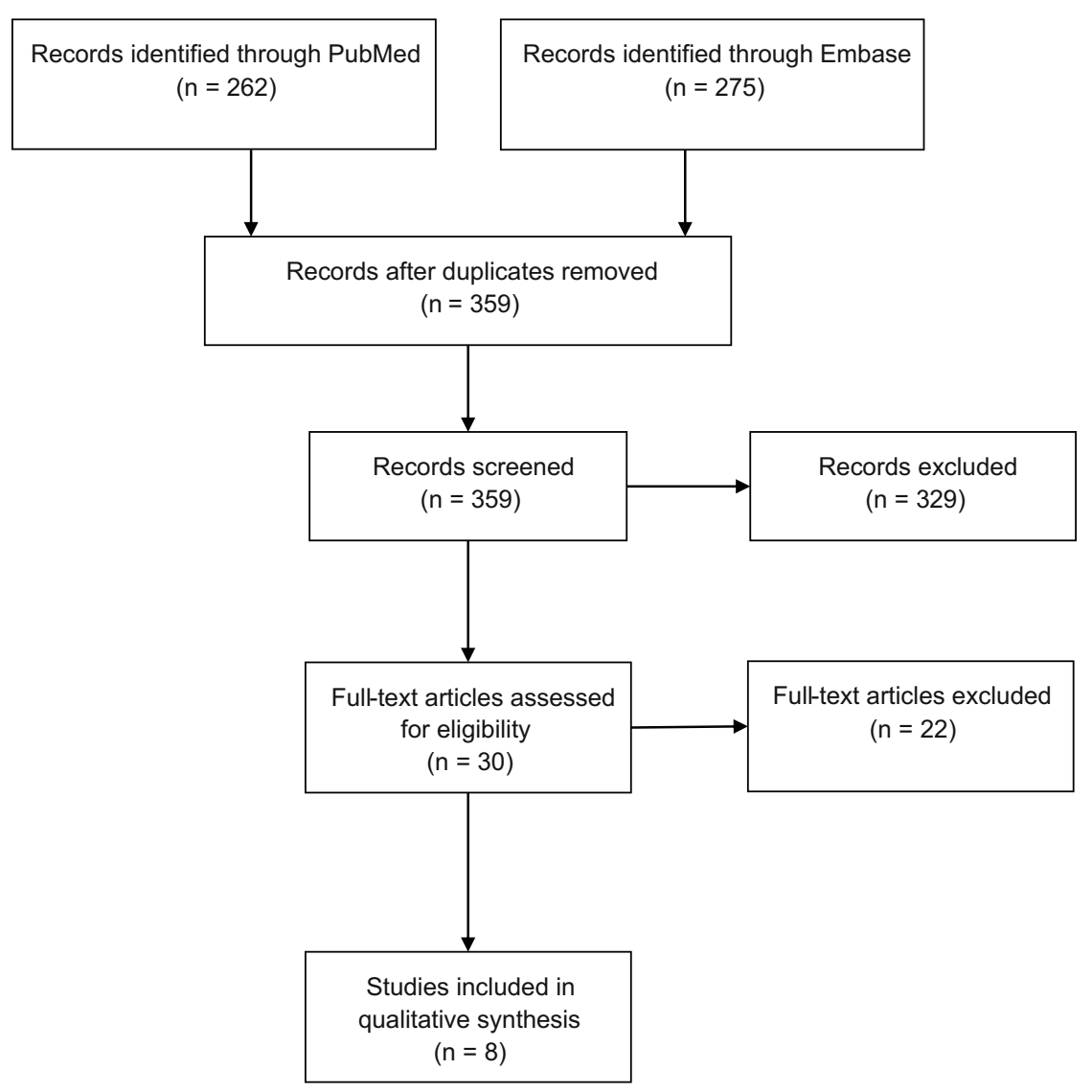


\section{Data extraction and analysis}

Identified papers were independently reviewed by two authors with final selection approved by the senior author. The data on presence of a hernia sac, liver herniation, length of hospital stay (LOS), number of days ventilated, pulmonary hypertension, requirement for patch repair, extracorporeal membrane oxygenation (ECMO) and survival was then extracted from the original publications. After summarizing the data, statistical analysis was feasible for all categorical outcome measures. Due to variations in some reporting data by authors on hospital LOS and number of days ventilated, consistent datasets only were consolidated in final review.

\section{Statistical analysis}

Chi-square and Fisher's exact tests were utilised to analyse categorical variables. A Significance level of $p \leq 0.05$ (twotailed) was set. Analyses were performed using JMP Pro, version 13.1.0 for Windows (SAS Institute Inc., Cary, NC, USA).

\section{Results}

The original search identified 537 articles. A total of 359 studies were then evaluated with screening of titles and abstracts after duplicates were excluded. Thirty papers met inclusion criteria in screening and were then selected for full text review. After full text review of 30 articles, eight papers met eligibility criteria and were selected for review (Fig. 1). All selected papers were retrospective single-centre cohort studies. All eligible papers and the extracted data are summarised in Table 1.

In total, there were 837 patients with congenital diaphragmatic hernia including 168 patients (20\%) with a hernia sac. Overall survival was significantly better in the patient groups with a hernia sac $(93 \%$ vs $73 \%, p<0.001)$. Requirement for patch repair of the defect was significantly more common among those without a hernia sac $(44 \%$ vs $23 \%, p<0.001)$. Pulmonary hypertension was manifested more often among $\mathrm{CDH}$ babies without a hernia sac $(64 \%$ vs $44 \%, p<0.001)$. Three studies compared the requirement for ECMO. Absence of a hernia sac was associated with more frequent ECMO utilization (34\% vs $15 \%$,

Table 1 Summary data-articles defining outcomes of $\mathrm{CDH}$ newborns with and without a hernia sac

\begin{tabular}{|c|c|c|c|c|c|c|}
\hline & Case numbers & Survival & Patch repair & Pulmonary hypertension & Liver herniation & $\begin{array}{l}\text { ECMO } \\
\text { requirement }\end{array}$ \\
\hline \multicolumn{7}{|l|}{ Zamora et al. (2013) } \\
\hline With a hernia sac & $30(22 \%)$ & $25 / 30(83 \%)$ & $6 / 29(21 \%)$ & $5 / 27(19 \%)$ & $23 / 30(77 \%)$ & $3 / 30(10 \%)$ \\
\hline Without a sac & $107(78 \%)$ & $79 / 107(74 \%)$ & $62 / 97(64 \%)$ & $54 / 102(53 \%)$ & $66 / 107(62 \%)$ & $47 / 107(44 \%)$ \\
\hline \multicolumn{7}{|l|}{ Spaggiari et al. (2013) } \\
\hline With a hernia sac & $18(26 \%)$ & $17 / 18(94 \%)$ & $0 / 18(0 \%)$ & $7 / 18(39 \%)$ & $4 / 18(22 \%)$ & N/A \\
\hline Without a sac & $52(74 \%)$ & $35 / 52(67 \%)$ & $4 / 52(11 \%)$ & $33 / 52(63 \%)$ & $11 / 5221 \%)$ & N/A \\
\hline \multicolumn{7}{|l|}{ Panda et al. (2013) } \\
\hline With a hernia sac & $10(14 \%)$ & $9 / 10(90 \%)$ & $0 / 10(0 \%)$ & $3 / 10(30 \%)$ & $2 / 10(20 \%)$ & N/A \\
\hline Without a sac & $60(86 \%)$ & $34 / 60(57 \%)$ & $6 / 60(10 \%)$ & $37 / 60(62 \%)$ & $14 / 60(23 \%)$ & N/A \\
\hline \multicolumn{7}{|l|}{ Grizelj et al. (2017) } \\
\hline With a hernia sac & $7(24 \%)$ & $7 / 7(100 \%)$ & $1 / 7(14 \%)$ & $5 / 7(71 \%)$ & $7 / 7(100 \%)$ & N/A \\
\hline Without a sac & $22(76 \%)$ & $7 / 22(32 \%)$ & $5 / 22(23 \%)$ & $17 / 22(81 \%)$ & $22 / 22(100 \%)$ & N/A \\
\hline \multicolumn{7}{|c|}{ Bouchgoul et al. (2018) } \\
\hline With a hernia sac & $17(24 \%)$ & $17 / 17(100 \%)$ & $2 / 17(12 \%)$ & $11 / 17(65 \%)$ & $6 / 17(35 \%)$ & N/A \\
\hline Without a sac & $55(76 \%)$ & $35 / 55(64 \%)$ & $24 / 48(50 \%)$ & $38 / 55(69 \%)$ & $27 / 55(49 \%)$ & N/A \\
\hline \multicolumn{7}{|l|}{ Aydin et al. (2019) } \\
\hline With a hernia sac & $26(14 \%)$ & $25 / 26(96 \%)$ & $7 / 26(27 \%)$ & N/A & $18 / 26(69 \%)$ & $4 / 26(15 \%)$ \\
\hline Without a sac & $162(86 \%)$ & $130 / 162(80 \%)$ & $58 / 162(36 \%)$ & N/A & $108 / 162(67 \%)$ & $57 / 162(35 \%)$ \\
\hline \multicolumn{7}{|c|}{ Levesque et al. (2019) } \\
\hline With a hernia sac & $14(20 \%)$ & $14 / 14(100 \%)$ & $6 / 14(43 \%)$ & $5 / 14(36 \%)$ & $6 / 14(43 \%)$ & N/A \\
\hline Without a sac & $57(80 \%)$ & $54 / 57(95 \%)$ & $30 / 57(53 \%)$ & $28 / 57(54 \%)$ & $17 / 57(30 \%)$ & N/A \\
\hline \multicolumn{7}{|l|}{ Oliver et al. (2019) } \\
\hline With a hernia sac & $46(23 \%)$ & N/A & $16 / 41(39 \%)$ & $23 / 41(56 \%)$ & N/A & $8 / 41(20 \%)$ \\
\hline Without a sac & $154(77 \%)$ & N/A & $90 / 130(69 \%)$ & $98 / 130(75 \%)$ & N/A & $33 / 130(25 \%)$ \\
\hline
\end{tabular}

N/A data not available 
$p<0.001)$. There were no significant difference(s) observed in the presence of liver herniation ('liver up') between the groups though 'liver up' was more common in newborns with a hernia $\operatorname{sac}(54 \%$ vs $49 \%, p=0.34)$ (Table 2$)$.

All six studies which analysed hospital/neonatal intensive care LOS reported shorter LOS in the $\mathrm{CDH}$ group with a hernia sac although this difference was only statistically significant in three of those six studies. Seven studies examined number of ventilation days and although all reported shorter duration among $\mathrm{CDH}$ newborns with a hernia sac, statistical significance was observed here in only two studies.

\section{Discussion}

This systematic review study has clearly shown that $\mathrm{CDH}$ newborns with a hernia sac have better overall survival outcomes and less severe pulmonary hypertension. Moreover, ECMO utilization and patch repair were equally less often required in newborns having a hernia sac noted at the timing of the operative repair of the diaphragm defect.

Some early reports have made effort to show that the presence of hernia sac may be associated with better survival [11, $14,15,18]$. However, difference(s) were not statistically significant in all these studies [16]. As pulmonary hypoplasia is a significant risk factor for mortality in newborns with $\mathrm{CDH}$ [10] and the presence of hernia sac is now reportedly associated with higher total foetal lung volumes by foetal medicine centres $[11,12]$, we postulate that the benefits in survival we now report from a systematic review of 'high quality' published studies here may be potentially linked with higher total lung volumes also preserved in the postnatal period in $\mathrm{CDH}$ infants surviving with a hernia sac.

Pulmonary hypertension is a key factor linked with mortality and morbidity in $\mathrm{CDH}[8,19]$. Only one study has reported a potential association between pulmonary hypertension and presence of a hernia sac in $\mathrm{CDH}$ [12]. The combined data we have now analysed clearly show a significant difference in frequency of pulmonary hypertensive episodes in $\mathrm{CDH}$ babies with and without a hernia sac. The better physiological outcomes observed in $\mathrm{CDH}$ newborns with a hernia sac are intriguing.

Prosthetic patch repair was required much less often in infants studied here with a hernia sac. Similar, independent finding(s) were reported in three of eight studies we have reviewed $[12,14,20]$. These findings strongly suggest smaller defect size (' $\mathrm{A}$ ' and ' $\mathrm{B}$ ' category type defects) associated with presence of a hernia sac. Interestingly, we observed that $\mathrm{CDH}$ cases with hernia sac were more often associated with liver herniation though the difference(s) were not statistically significant vs infants with no hernia sac. Intrathoracic liver herniation is considered to be a strong prognostic marker in foetal $\mathrm{CDH}$ and associated with poor outcome(s) $[7,10,21]$. In our current study, we found that more than half of the $\mathrm{CDH}$ cases we analysed with a hernia sac had reportedly liver herniation and yet a very high survival rate of almost $93 \%$. It therefore seems evident that the presence of a hernia sac in some way may be a 'protective' native biological barrier favouring preservation of lung growth in affected foetuses. Identification of a hernia sac 'in utero' with foetal MRI imaging may potentially serve as a new prognostic marker for better outcome(s).

Requirement for ECMO was reported in three studies we analysed $[12,20,21]$ with one study clearly showing statistically significant difference in outcome [12]. The combined data from all three studies established that ECMO was less often required in infants with a hernia sac. Although we were unable from the current publications to fully analyse data on hospital LOS and number of days ventilated, the emerging evidence suggests that the presence of $\mathrm{CDH}$ hernia sac is associated with shorter $\operatorname{LOS}[12,20,21]$, and also fewer hospital days requiring ventilation $[12,16]$. These findings are most likely reflective of more favourable physiology with better lung growth preserved in infants (see earlier) also with reduced rates of pulmonary hypertension.

Some limitation(s) of the current systematic review relate to variations in methods of data reporting from the published studies. Hence, we were unable to fully analyse metrics on hospital LOS and total number of days ventilated. As all included papers were single-centre studies, we believe that the study authors reporting of pulmonary hypertension was standardised in individual units minimizing centre bias. Finally, all included studies analysed were retrospective cohort populations.

This study has demonstrated that the presence of a hernia sac in $\mathrm{CDH}$ is associated with survival benefits. These finding(s) may be likely related to $\mathrm{CDH}$ newborns having more favourable physiology such as reduced rates of pulmonary

Table 2 Comparison of outcomes between $\mathrm{CDH}$ newborns with and without a hernia sac

\begin{tabular}{|c|c|c|c|c|c|}
\hline & Survival & Patch repair & Pulmonary hypertension & Liver herniation & ECMO requirement \\
\hline With hernia sac $n=168(20 \%)$ & $114 / 122(93 \%)$ & $38 / 162(23 \%)$ & $59 / 134(44 \%)$ & $66 / 122(54 \%)$ & $15 / 97(15 \%)$ \\
\hline Without sac $n=669(80 \%)$ & $374 / 515(73 \%)$ & $279 / 628(44 \%)$ & $305 / 478(64 \%)$ & $243 / 493(49 \%)$ & $137 / 399(34 \%)$ \\
\hline$P$ value & $<0.001$ & $<0.001$ & $<0.001$ & 0.34 & $<0.001$ \\
\hline
\end{tabular}


hypertension and/or smaller diaphragm defects ('A' and ' $\mathrm{B}$ ' category) which are amenable to primary closure and repair.

Authors' contribution All authors contributed to the study conception and design. Material preparation, data collection, and analysis were performed by AR and AS and PDL. The first draft of the manuscript was written by AR and all authors commented on previous versions of the manuscript. All authors read and approved the final manuscript.

Funding information AR reports research grants from Clinical Research Institute HUCH, Emil Aaltonen Foundation and Turku University Foundation.

\section{Compliance with ethical standards}

Conflict of interest The authors declare that they have no conflict of interest.

Ethical approval This article does not contain any studies with human participants or animals performed by any of the authors.

Open Access This article is licensed under a Creative Commons Attribution 4.0 International License, which permits use, sharing, adaptation, distribution and reproduction in any medium or format, as long as you give appropriate credit to the original author(s) and the source, provide a link to the Creative Commons licence, and indicate if changes were made. The images or other third party material in this article are included in the article's Creative Commons licence, unless indicated otherwise in a credit line to the material. If material is not included in the article's Creative Commons licence and your intended use is not permitted by statutory regulation or exceeds the permitted use, you will need to obtain permission directly from the copyright holder. To view a copy of this licence, visit http://creativecommons.org/licenses/by/4.0/.

\section{References}

1. Moore KL, Persaud TVN (2003) The developing human: clinically oriented embryology, 7th edn. Saunders, Philadelphia

2. Torfs CP, Curry CJ, Bateson TF, Honoré LH (1992) A populationbased study of congenital diaphragmatic hernia. Teratology 46 : 555-565

3. Langham MR Jr, Kays DW, Ledbetter DJ, Frentzen B, Sanford LL, Richards DS (1996) Congenital diaphragmatic hernia. Epidemiology and outcome. Clin Perinatol 23:671-688

4. Butler MW, Stolar CJ, Altman RP (1993) Contemporary management of congenital diaphragmatic hernia. World J Surg 17:350-355

5. Carmichael SL, Ma C, Lee HC, Shaw GM, Sylvester KG, Hintz SR (2020) Survival of infants with congenital diaphragmatic hernia in California: impact of hospital, clinical, and sociodemographic factors. J Perinatol 40:943-951

6. Losty PD (2014) Congenital diaphragmatic hernia: where and what is the evidence? Semin Pediatr Surg 23:278-282

7. Arora M, Bajpai M, Soni TR, Prasad TR (2000) Congenital diaphragmatic hernia. Indian J Pediatr 67:665-670
8. Dillon PW, Cilley RE, Mauger D, Zachary C, Meier A (2004) The relationship of pulmonary artery pressure and survival in congenital diaphragmatic hernia. J Pediatr Surg 39:307-312

9. Putnam LR, Harting MT, Tsao K, Morini F, Yoder BA, Luco M, Lally PA, Lally KP (2016) Congenital diaphragmatic hernia defect size and infant morbidity at discharge. Pediatrics 138:e20162043

10. Oluyomi-Obi T, Kuret V, Puligandla P, Lodha A, Lee-Robertson H, Lee K, Somerset D, Johnson J, Ryan G (2017) Antenatal predictors of outcome in prenatally diagnosed congenital diaphragmatic hernia (CDH). J Pediatr Surg 52:881-888

11. Spaggiari E, Stirnemann J, Bernard JP, De Saint BL, Beaudoin S, Ville Y (2013) Prognostic value of a hernia sac in congenital diaphragmatic hernia. Ultrasound Obstet Gynecol 41:286-290

12. Zamora IJ, Cass DL, Lee TC, Welty S, Cassady CI, Mehollin-Ray AR, Fallon SC, Ruano R, Belfort MA, Olutoye OO (2013) The presence of a hernia sac in congenital diaphragmatic hernia is associated with better fetal lung growth and outcomes. J Pediatr Surg 48:1165-1171

13. Panda SS, Bajpai M, Srinivas M (2013) Presence of hernia sac in prediction of postoperative outcome in congenital diaphragmatic hernia. Indian Pediatr 50:1041-1043

14. Bouchghoul H, Marty O, Fouquet V, Cordier A-G, Senat M-V, Saada J, Mokhtari M, Le Sache N, Martinovic J, Benachi A (2018) Congenital diaphragmatic hernia has a better prognosis when associated with a hernia sac. Prenat Diagn 38:638-644

15. Grizelj R, Bojanić K, Vuković J, Novak M, Weingarten TN, Schroeder DR, Sprung J (2017) Hernia sac presence portends better survivability of isolated congenital diaphragmatic hernia with "liver-up". Am J Perinatol 34:515-519

16. Levesque M, Derraugh G, Schantz D, Morris MI, Shawyer A, Lum Min SA, Keijzer R (2019) The presence of a hernia sac in isolated congenital diaphragmatic hernia is associated with less disease severity: a retrospective cohort study. J Pediatr Surg 54:899-902

17. Moher D, Liberati A, Tetzlaff J, Altman DG (2009) Preferred reporting items for systematic reviews and meta-analyses: the PRISMA statement. BMJ (Clinical research ed) 339:b2535

18. Heiwegen K, van Heijst AF, Daniels-Scharbatke H, van Peperstraten MC, de Blaauw I, Botden SM (2020) Congenital diaphragmatic eventration and hernia sac compared to $\mathrm{CDH}$ with true defects: a retrospective cohort study. Eur J Pediatr 179:855-863

19. Cochius-den Otter S, Schaible T, Greenough A, van Heijst A, Patel N, Allegaert K, van Rosmalen J, Tibboel D (2019) The CoDiNOS trial protocol: an international randomised controlled trial of intravenous sildenafil versus inhaled nitric oxide for the treatment of pulmonary hypertension in neonates with congenital diaphragmatic hernia. BMJ Open 9:e032122

20. Oliver ER, DeBari SE, Adams SE, Didier RA, Horii SC, Victoria T, Hedrick HL, Adzick NS, Howell LJ, Moldenhauer JS, Coleman BG (2019) Congenital diaphragmatic hernia sacs: prenatal imaging and associated postnatal outcomes. Pediatr Radiol 49:593-599

21. Aydin E, Lim F-Y, Kingma P, Haberman B, Rymeski B, Burns P, Peiro JL (2019) Congenital diaphragmatic hernia: the good, the bad, and the tough. Pediatr Surg Int 35:303-313

Publisher's note Springer Nature remains neutral with regard to jurisdictional claims in published maps and institutional affiliations. 